\title{
Embedding thermal comfort into retrofitting design to prevent humidity problems and unintended consequences-a literature review Athina Petsou ${ }^{\mathrm{a}}$, Hector Altamirano ${ }^{\mathrm{a}}$, Robyn Pender ${ }^{\mathrm{b} *}$ \\ a UCL Institute of Environmental Design and Engineering, London, UK $b$ Historic England, UK
}

\begin{abstract}
In Europe, older buildings are responsible for $40 \%$ of the total primary energy consumption. This gives great potential for reducing energy and $\mathrm{CO}_{2}$ emissions. However, during the last decade, the retrofit processes applied to existing buildings have resulted in unintended consequences such as overheating, mould growth and the increase of indoor pollutants. In practice, retrofit is dominated by energy and economical approaches that concentrate on specific standards of U-Values and increasing airtightness. Thermal comfort, although a requirement, is not taken into account during the retrofit design process. This paper discusses how those unintended consequences can be minimised if thermal comfort is properly considered and assessed prior to retrofit interventions.
\end{abstract}

Peer-review under the responsibility of the organizing committee of the ICMB21.

Keywords: Thermal comfort; Humidity; Mould; Retrofit

\section{Introduction}

Reducing energy consumption in the built environment is one of the severest challenges of our times. In Europe, older buildings constitute $25 \%$ of the building stock and are responsible for $40 \%$ of the total primary energy consumption [1]. This gives great potential for reducing energy and $\mathrm{CO}_{2}$ emissions. Fuel poverty and energy justice as well as the need to reduce energy consumption have led to social policies regarding buildings energy retrofit. The relationship between thermal comfort and fuel poverty has been demonstrated [2]. Internal temperatures in fuel-poor households have been found to be for most of the time outside thermal comfort ranges, which is considerably different from non-fuel-poor households. However, the retrofit processes applied to existing buildings have resulted, in a considerable number of cases, in unintended consequences such as condensation, mould growth, the increase of indoor airborne pollutants levels $\left(\mathrm{PM}_{2.5}\right.$, VOCs, radon, etc.), internal overheating not just during summer periods, as well as effects on human comfort, health and wellbeing [3,5-8]. Another alarming result is the, still, considerable emissions of GHG due to the 'rebound effect'[6]. In practice, retrofit is dominated by energy and economical approaches that concentrate on U-Values increasing airtightness in buildings [4-5], where the users' behaviour and thermal comfort needs are not taken into account. Implementation of advanced performance standards in retrofit may require more careful consideration [8]. It would be beneficial to prioritize thermal comfort with minimum energy use in the retrofitting of historical buildings taking into account also, the technical compatibility and minimum effect of the building structure.

\section{Methodology}

In order to understand how thermal comfort is connected with the unintended consequences of retrofit processes and the role that thermal comfort play in the design and implementation of retrofit interventions, we performed a search of the literature across the following disciplines: building physics, construction technology and conservation practices, health and well-being and social sciences. We searched the following electronic databases: Web of Knowledge, Science Direct, Scopus, Social Science Research Network. In addition, we researched the European Union and UK Government legislative and policy documents, reports and guidance from Historic England and NGOs and organizations involved in the retrofitting process, websites and newspaper articles.

\section{Retrofit Design and Thermal Comfort}

Although professionals acknowledge thermal comfort as a key priority [10-12], and thermal comfort percentage is used as an indicator of a successful retrofit, there is no specific process for designing and assessing thermal comfort as part of carbon or energy retrofitting of existing buildings. Even when thermal comfort is taken into account, it is reduced to a consideration of air temperatures, neglecting other, maybe more important, parameters of discomfort, such as draughts or radiant temperature [13]. Yet a better appreciation of those parameters can lead to retrofit interventions that are less invasive to the building envelope, healthier for the indoor environment, and more appropriate for the conservation of the heritage values of buildings. An added advantage is that these retrofit approaches generally use less carbon and energy to produce, install, and operate.

\footnotetext{
*Athina Petsou.00447503649172. Athinapetsou19@ucl.ac.uk
} 


\section{ICMB21}

According to de Dear, we must not only reconsider the approach taken over the past 100 years to define and assess indoor thermal climatic parameters and Standards, but also quantify the influence of comfort factors on occupants, and how these are affected by the building envelope [14] (Figure 1).

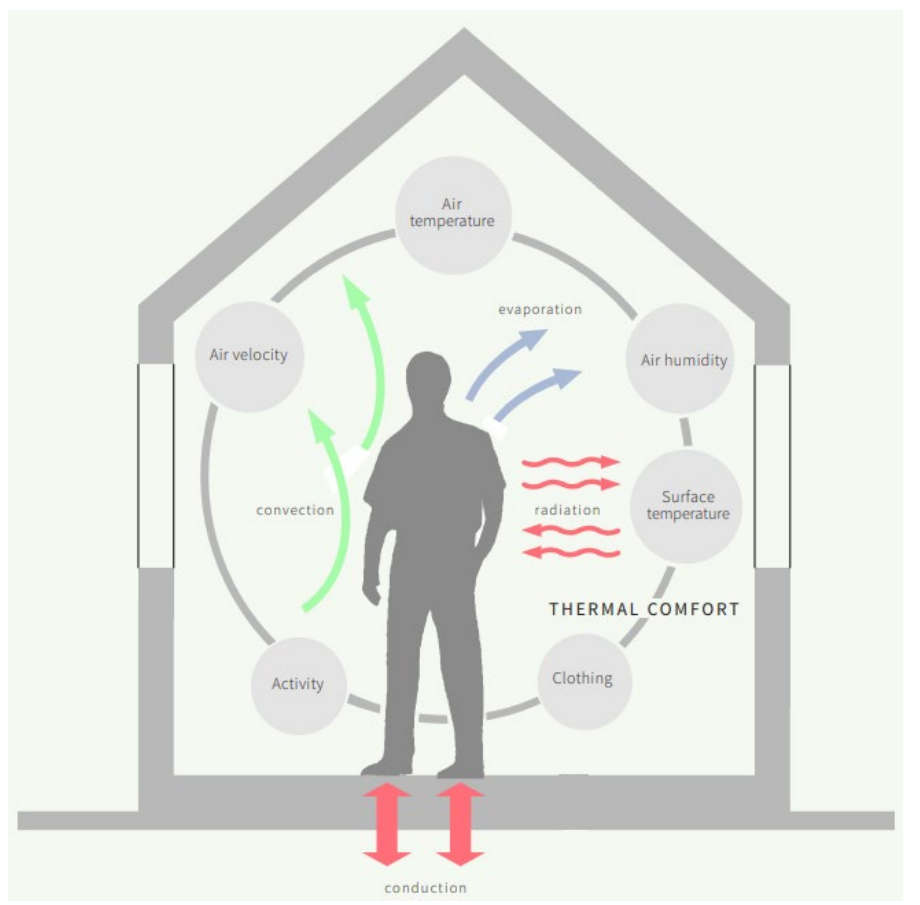

At the moment, it is almost universally accepted that for any indoor space to be comfortable and useable, the air temperature must be controlled. And yet, as we know, a controlled indoor temperature does not guarantee thermal comfort [15]. We need to move away from comfort as a range of temperatures and see it for what it is: the complex interaction of environmental, behavioural, psychological and social factors [16]. Clothing factor is one parameter that has been researched and integrated into comfort standards, but other overlooked factors such as body heat loss through radiation and user's behaviour may be still more important. People living in cold houses and experiencing fuel poverty dealt passively with these issues, e.g., wear blankets out of bed and more clothes or simple consume hot drinks and food. There is also room for more research on how different situations constrain occupant behaviour and the effect that group behaviour has on the individual (noting that "comfortable conditions" is a social notion that reflects current values, and changes over time [17]).

Figure 1. Physical Factors affecting thermal comfort, Energy Efficiency and Historic Buildings, Historic England

Putting users at the centre of the approach could significantly affect the energy outcome of a retrofit intervention. Thermal comfort should provide a compass in the design of the retrofit process. Finding the parameters affecting thermal comfort and how thermal comfort can be meaningfully used, investigate the conditions under which people feel comfortable or uncomfortable, as well as defining the criteria practitioners could employ and incorporate in their design project are the aims of this research project. In a second stage, the project will a) explore how thermal comfort is understood, researched and applied by practitioners during the design of the retrofit process and b) investigate the specific conditions and parameters affecting the thermal comfort of historic building users to derive the information to be considered in the establishment of thermal comfort criteria for retrofit.

\section{References}

[1] Frances Bean, Jonathan Volt, Vivian Dorizas, Eleftherios Bourdakis, Dan Staniaszek, Andrea Roscetti, Lorenzo Pagliano (2019), Future Proof Buildings for All Europeans, A guide to implement the energy performance of building directive (2018/844), Buildings Performance Institute Europe (BPIE)

[2] Healy, John D, and Clinch, J.Peter. "Quantifying the Severity of Fuel Poverty, Its Relationship with Poor Housing and Reasons for Non-investment in Energy-saving Measures in Ireland." Energy Policy 32.2 (2004): 207-20. Web.

[3] Matthew Collins \& Seraphim Dempsey (2019) Residential energy efficiency retrofits: potential unintended consequences, Journal of Environmental Planning and Management, 62:12, 2010-2025, DOI: $10.1080 / 09640568.2018 .1509788$

[4] Webb, Amanda L. "Energy Retrofits in Historic and Traditional Buildings: A Review of Problems and Methods." Renewable \& Sustainable Energy Reviews 77 (2017): 748-59. Web.

[5] M. Davies, T. Oreszczyn,The unintended consequences of decarbonising the built environment: A UK case study, Energy and Buildings 46 (2012) 80-85

[6] Forman, Timothy. "Practice, Policy and Professional Roles: Unintended Consequences and Performance Gaps in Uk Domestic Solid Wall Insulation Retrofit Projects." (2015). Web.

[7] Shrubsole, C, Macmillan, A, Davies, M, and May, N. "100 Unintended Consequences of Policies to Improve the Energy Efficiency of the UK Housing Stock." INDOOR AND BUILT ENVIRONMENT, 23 (3) 340 - 352. (2014)

[8] Mavrogianni, A., Oikonomou, E., Das, P., Davies, M., Raslan, R., Jones, B., ... Shrubsole, C. (2013). The unintended consequences of energy efficient retrofit on indoor overheating and air pollution risk in a typical Edwardian mid-terraced house. Proceedings from FutureBuild 2013, Bath, UK

[9] https://www.heritage-survey.org/problems-caused-by-retrofitting, 15.11.2020

[10] Warmer Bath: A Guide to Improving the Energy Efficiency of Traditional Homes in the City of Bath.

[11] EN 16883:2017 Conservation of Cultural Heritage - Guidelines for improving the energy performance of historic buildings

[12] Akkurt GG, Aste N, Borderon J, Buda A, Calzolari M, Chung D, et al. Dynamic thermal and hygrometric simulation of historical buildings: Critical factors and possible solutions. Renew Sustain Energy Rev [Internet]. 2020;118(October 2019):109509. Available from: https://doi.org/10.1016/j.rser.2019.10950

[13] "BS EN 15251:2007: Indoor Environmental Input Parameters for Design and Assessment of Energy Performance of Buildings Addressing Indoor Air Quality, Thermal Environment, Lighting and Acoustics." (2008). Web.

[14] R. de Dear, Thermal comfort in practice, Indoor Air 2004; 14: 32

[15] Fergus Nicol \& Susan Roaf (2017) Rethinking thermal comfort, Building Research \& Information, 45:7, 711-716, DOI: 10.1080/09613218.2017.1301698

[16] Robyn Pender, Daniel J. Lemieux, The Road Not Taken: Building Physics, and Returning to First Principles in Sustainable Design, Atmosphere 2020, 11(6), 620; https://doi.org/10.3390/atmos11060620

[17]J. F. Nicol \& M. A. Humphreys (1973) Thermal comfort as part of a self-regulating system, Building Research and Practice, 1:3, 174-179 